\title{
Uma Análise da Obra Plantas Tóxicas do Brasil (1871), de autoria do Médico-Botânico Joaquim Monteiro Caminhoá
}

\section{An Analysis of the Plants Toxics of Brazil (1871), by the Physician-Botanist Joaquim Monteiro Caminhoá}

\author{
DOI: $10.46814 / 1 \mathrm{ajdv3n3-011}$
}

Recebimento dos originais: 01/05/2021

Aceitação para publicação: 30/06/2021

\section{Alex Gonçalves Varela}

Professor Adjunto do Departamento de História da Universidade do Estado do Rio de Janeiro Endereço Institucional: Rua São Francisco Xavier, 524, Maracanã, Rio de Janeiro, Brasil. CEP.: 20550-900.

E-mail: alexvarelarj@terra.com.br

\author{
Gabriel Vieira \\ Mestrando do Programa de Pós-graduação em História das Ciências e da Saúde da Casa de Oswaldo \\ Cruz/FIOCRUZ \\ Endereço Institucional: Centro de Documentação e História da Saúde (CDHS) - sala 307. Fundação \\ Oswaldo Cruz Av. Brasil, 4365, Manguinhos - Rio de Janeiro. CEP 21040-900 \\ E-mail: gabriel-ace@hotmail.com
}

\section{RESUMO}

Temos como objeto de análise a obra Das Plantas Tóxicas do Brasil (1871), de autoria do médicobotânico Joaquim Monteiro Caminhoá. Personagem bastante citado nos manuais de história da medicina, porém sua trajetória de vida ainda não foi devidamente estudada, e suas produções científicas não foram analisadas criticamente. Portanto, há lacunas que estimulam a continuidade dos estudos sobre o referido personagem, e a sua contribuição para o processo de emergência e consolidação das ciências naturais do Império do Brasil.

Palavras-Chaves: História das Ciências, Joaquim Monteiro Caminhoá, Botânica, Império do Brasil.

\section{ABSTRACT}

The object of analysis is The Plants Toxics of the Brazil (1871), by the physician-botanist Joaquim Monteiro Caminhoá. Character quite mentioned in medical history manuals, but his life trajectory has not been properly studied, and his scientific productions have not been critically analyzed. Therefore, there are gaps that encourage the continuity of studies on this character, and his contribution to the process of emergence and consolidation of the natural sciences of the Empire of Brazil.

Key-words: History of Sciences, Joaquim Monteiro Caminhoá, Botany, Empire of Brazil.

\section{INTRODUÇÃO E OBJETIVOS}

Temos como objeto de análise a tese de concurso para a cadeira de Botânica Médica da Faculdade de Medicina do Rio de Janeiro (FMRJ), de autoria de Joaquim Monteiro Caminhoá, 
publicada no ano de 1871, e tem como título Das Plantas Tóxicas do Brazil. Caminhoá ocupava a função de professor da FMRJ na qualidade de Opositor da Secção de Ciências Acessórias. E, tentava o concurso para se tornar Lente Catedrático da Cadeira de Botânica, que compunha o conjunto de disciplinas do segundo ano.

Joaquim Monteiro Caminhoá (1836-1896) foi um dos mais atuantes cientistas do Império do Brasil. Ele graduou-se em medicina pela Faculdade de Medicina da Bahia no ano de 1858, e realizou o seu doutorado na mesma instituição. A seguir, ingressou no Corpo de Saúde da Armada, prestando serviços como segundo cirurgião atuando em hospitais e navios. Foi professor da Cadeira de Botânica e Zoologia da Faculdade de Medicina do Rio de Janeiro, e da cátedra de história natural no Internato do Imperial Colégio de Pedro II. Foi sócio de inúmeras sociedades científicas nacionais e estrangeiras, como a Academia Imperial de Medicina, a Associação Brasileira de Aclimação, a Academia Brasileira de Medicina Militar, a Sociedade de Botânica da França, e a Sociedade de Ciências Naturais de Edimburgo. Foi membro adjunto da comissão brasileira na Exposição Universal de Viena, realizada de maio a novembro de 1873. Publicou inúmeros artigos e livros, dentre os quais salienta-se a obra Elementos de Botânica Geral e Médica, cuja primeiro volume foi publicado em 1877 seguido por mais dois números.

Joaquim Monteiro Caminhoá foi um cientista que teve uma carreira consolidada e reconhecida nacional e internacionalmente. $\mathrm{O}$ estudioso se dedicou a produzir conhecimento científico sobre questões médicas e botânicas. Estamos nos dedicando a estudar a sua trajetória acadêmica, que ainda não foi devidamente estudada, bem como as suas produções científicas ainda não foram analisadas profundamente. Dessa forma, há lacunas que precisam ser preenchidas pelos estudiosos que se dedicam a pesquisar as relações ciências e trajetórias, e caminhos amplos e profícuos que merecem ser explorados e estimulam novas reflexões. (Varela, 2019; 2021) Conforme já informarmos, a produção científica de Caminhoá que iremos analisar é Das Plantas Tóxicas do Brasil.

\section{ANÁLISE DAS PLANTAS TÓXICAS DO BRASIL (1871)}

Antes de iniciar a primeira parte do texto, Caminhoá aborda três tópicos. Primeiro escreveu uma dedicatória destinada à Sociedade Velosiana. Em seguida, elaborou uma justificativa para o texto. E, por último, o autor redigiu um breve histórico sobre o uso pelo homem de substâncias venenosas proveniente de plantas tóxicas.

Caminhoá dedica essa obra à Sociedade Velosiana. Esta, reunida pela primeira vez em 27 de julho de 1850, foi um dos principais fóruns de discussão e divulgação de atividades e contribuições científicas no Brasil Império. A Sociedade tinha como fim ""indagar, coligir e estudar todos os objetos pertencentes à história natural do Brasil; e juntamente averiguar e interpretar as palavras indígenas, 
com que forem designados". (Casa de Oswaldo Cruz/ Fiocruz, 05/06/2020) Em sua dedicatória, Caminhoá diz que a Sociedade Velosiana é a única sociedade de naturalistas do Brasil, "sendo um foco do qual pode o país esperar muita luz para a resolução de problemas de máxima importância”. (Caminhoá, 1871, VII)

Ao justificar seu texto, Caminhoá exclamou que "Não há um só trabalho nacional, ou estrangeiro sobre - Plantas Tóxicas do Brasil!”. (Idem. Ibidem, X) E, argumentou que o trabalho que ora apresentava era a primeira monografia sobre o assunto. Assim afirmou:

Não ha um só trabalho nacional, ou estrangeiro sobre - Plantas tóxicas do Brasil ! O nosso, de pena tão humilde, vai ser a $1^{\text {a }}$ Monografia sobre o assunto ! E isso em um país que, na brilhante frase de St. Hillaire, é o Éden do reino vegetal! Em um país essencialmente agrícola e pastoril! Felizmente o fogo sagrado no Brasil ainda não se extinguiu completamente no templo da ciência. Alguns, muito poucos é verdade, dos sacerdotes que o veneram, conservam ou pelo menos ensinam a conservar a chama, embora pálida e lampejante. (Idem. Ibidem, X)

O autor fez questão de salientar o esforço exercido por ele de compilar a bibliografia sobre o assunto, sendo necessário pesquisá-la em bibliotecas públicas ou na de particulares. Nestas últimas, Caminhoá sublinhou a importância de "alguns cavalheiros" que lhe franquearam o acesso aos materiais ou deixaram consultá-la em suas própria residência. Muitos foram seus colaboradores, "conspícuos homens da ciência", dentre os quais podemos mencionar o Conselheiro Francisco Freire Alemão (1797-1874), Custodio Alves Serrão (1799-1873), Conselheiro Henrique Pedro Carlos de Beaurepaire Rohan (1812-1894), Guilherme Capanema (1824-1908), Nicolau Joaquim Moreira (1824-1894), Ladislau de Souza Mello Netto (1838-1894), Auguste François Marie Glaziou (1828- 1906), entre outros, homens que têm como característica em comum o estudo das ciências naturais.

Em especial mencionou Capanema e Beaurepaire Rohan, que "perderam largas horas a instruírem-me sobre as propriedades das diversas plantas que eles estudaram em suas peregrinações científicas pela diferentes províncias do Império", bem como a "amabilidade" de Nicolau Moreira, e Ladislau Neto, que "foram do maior proveito para o resultado do meu trabalho, como vereis das transcrições e citações que faço em relação a cada planta”. (Idem. Ibidem, IX-X) Fez questão de sublinhar também a "bondade" de Custódio Alves Serrão, o qual chamou de "Belisário da Ciência", e que colocou a disposição de caminhoá "seu tesouro de saber, e sua memória". (Idem. Ibidem, X)

E, um agradecimento especial conferiu a Freire Alemão, o "Decano da Botânica Brasileira", este sábio cuja

bondade de coração se traduzem facilmente em sua fisionomia alegre e bondosa e em sua fronte nobre, aí está, para mostrar, como em uma idade avançada, depois de inúmeros serviços prestados ao Brasil, ou melhor ao mundo, porque a Ciência não tem pátria, evita os gozos da vida banal, e da sociedade indiferente, e emprega todas as tépidas horas do inverno de sua vida no estudos dos seres naturais, dos vegetais da pátria! 
Oxalá não tenham o Brasil e a Ciência de perder os inúmeros e perfei produzidos com tanta consciência e dedicação no seio de seu agradável retiro! Preza a Deus que tantos centenares de plantas novas do Brasil, não descritas ainda antes dele, não tenham de servir para glórias de outros!

Deus inspire nossos homens de governo, e faça que eles, dominados de patriotismo, como os cremos, mandem imprimir aqueles trabalhos; lembrados de que "um povo é tanto mais admirado, quanto maior número de sábios conta em seu seio".

Rendido esse tributo de homenagem ao meu, e ao Vosso Mestre, digo cheio de orgulho: que o meu trabalho, pelas razões expostas, e mais porque contém esclarecimentos fornecidos por eles, e também por outros homens beneméritos da ciência, não pode deixar de ser acolhido por vós. (Idem. Ibidem, XI)

Ao redigir um breve histórico sobre o uso das substâncias tóxicas fornecidas pelas plantas, Caminhoá citou os egípcios e romanos, que não somente as usavam como arma do suicida, mas como instrumento da lei.

Citou também o haxixe, utilizado bastante pelos árabes para se "embriagarem, e experimentarem os prazeres da visão que lhes aparecem durante o sono provocado por esta substância”. (Idem. Ibidem, p. 1) No meio científico, argumentou Caminhoá, o haxixe é conhecido como o "Cânhamo da índia (Cannabis indica), de cujas sumidades floridas preparam um decoto, e um eleituário, a que eles denominam Dawamesc!” (Idem. Ibidem, p. 2) .

Informou também na Grécia e na Roma antigas, o suco da cicuta, e do Hyoscyamus era "levado na taça mortífera em nome da lei e da justiça". (Idem. Ibidem, p. 2)

Na primeira parte do texto, Caminhoá expôs que o objetivo a ser trabalhado é a botânica aplicada à toxicologia. Antes, porém, trata de elucidar algumas definições, como o que seria uma planta considerada tóxica ou venenosa. Em suas palavras:

De acordo com a maior parte dos toxicologistas (...) consideramos venenosa, ou tóxica - toda planta, que, sendo absorvidos pela economia animal seus sucos, ou melhor seus princípios ativos, produz alterações graves da saúde, ou a morte. (Idem. Ibidem, p. 3)

Ou seja, as plantas ditas tóxicas não se tratam apenas de venenos, como também medicamentos aplicados de forma ordinária, sempre sendo necessário se atentar para a dosagem, vacuidade do estômago, idade, entre outros aspectos. Contudo, esse estudo tem um foco primário nas substâncias venenosas. (Idem. Ibidem, p. 4)

De acordo com o autor, para classificarmos uma planta de tóxica se faz necessária a apreciação de várias circunstâncias.

A primeira delas são as propriedades inerentes às diversas famílias. Caminhoá informa que há plantas, que, pelo simples fato de pertencerem a certas Famílias, se tornam suspeitas quanto à sua ação. Citou algumas das famílias mais comuns de serem interpretadas como tóxicas, tais como as 
Loganiaceas, Apocynaceas, Solanaceas, Euphorbiaceas, Ranunculaceas, Cogumellos ou Fungos, Umbelliferas, Colchicaceas, Papaveraceas, Asclepiaceas.

Caminhoá argumentou que em outras Famílias, em que há uma grande quantidade de plantas familiares, merecem ser consideradas com atenção aquelas que não forem muito conhecidas. Dentre os exemplos que o botânico apresentou encontram-se: as Cucurbitaceas, que a par do melão, melancia, pepino, abóbora, também se encontram a bryonia, a coloquintida, o elaterio, e outras venenosas; as Araceas, oferecem o Arum vulgare, e alguns outros alimentares. Entretanto, o Arum maculatum, Arum italicum, Arum dracunculus, entre outros, podem ocasionar acidentes graves; as Caparidaceas, que embora tenham algumas comestíveis, como o Mussambê (gênero cleome), possui também algumas venenosas.

Segundo Caminhoá, muitos toxicologistas classificam os envenenamentos pelos vegetais, segundo suas famílias. Exemplos podem ser vistos nos casos das Solaneasvirosas, Strychnaceas (hoje Loganiaceas) e Ranunculaceas. Isso se dá devido plantas semelhantes em suas organografias, morfologias, habitação, entre outros fatores, comumente compartilhar algumas propriedades.

$\mathrm{O}$ autor argumentou que a cada grupo de plantas, naturalmente semelhantes, quanto à sua organografia, morfologia, habitação, facies, entre outros, compete um determinado número de propriedades igualmente comuns. Tal consideração vale tanto para as plantas venenosas, como para as que não são.

Apesar disso, o autor aponta que existem exceções, como o Abutilon venenosum, planta nimiamente tóxica, que pertence a família das Malvaceas.

Sobre as doses necessárias para o envenenamento humano, Caminhoá argumentou que poderiam variar de acordo com a planta de origem do veneno. Algumas com uma dose muito pequena já seriam suficientes para levar um ser humano à morte em questão de minutos, como algumas Loganiaceas e Apocynaceas. Caminhoá exemplificou com as muitas tribos existentes, tanto no Brasil, como na Ásia, África e Oceania, que envenenavam suas flechas nos sucos daquelas duas Famílias supracitadas. Um desses venenos que é relativamente famoso é o Curare. Por sua vez, ha algumas substâncias que precisam de uma quantidade bem maior de doses para poder gerar efeito semelhante, como o Manacá, Brunsfelsia uniflora (de Plum.), Franciscea uniflora (de Mart.), a Erva de rato, entre outras. (Idem.Ibidem, p. 6)

Caminhoá argumentou, levando em consideração premissas toxicológicas, que as plantas venenosas atuam de forma distinta nos órgãos dos animais, podendo ser classificadas e nomeadas de formas diferentes de acordo com aquela atuação. A manifestação dos sintomas tóxicos depende de circunstâncias mais ou menos variáveis. O local do animal onde acontece o contato com o veneno também é um fator que influência seu efeito. O estômago seria um local onde a absorção do veneno 
ocorreria de forma mais fácil, porém fatores como o suco gástrico poderia modificar ou decompor esse veneno. Em função desta constatação, Caminhoá chegou ao seguinte corolário: “O corolário que daí se tira é, que tanto mais seguro será o efeito da substância tóxica, quanto mais vazio estiver o estômago". (Idem. Ibidem, p. 7) Para contornar tal situação, argumentou o cientista, a inoculação hipodérmica seria uma opção mais segura de aplicação daqueles princípios. (Idem. Ibidem, p. 7)

Segundo Caminhoá, algumas experiências já feitas pela ciência comprovariam aquela possível alteração dependendo da forma em que o veneno tenha contato com o corpo do animal. Essas experiências foram feitas com o Curare e outros tipos de substâncias, como o veneno de serpentes, ou cobras venenosas, aplicado diretamente no estômago de coelhos e outros animais, sem ter resultados fatais. Sublinhou Caminhoá que as mesmas experiências "teriam dado resultados terríveis se aqueles líquidos fossem inoculados.” (Idem. Ibidem, p. 7)

Para os vegetais, o cientista argumentou que aquela consideração supracitada também tinha validade. Na maioria dos venenos vegetais, observou o estudioso, eles têm uma certa uma predileção pelos centros nervosos. O envenenamento por meio dos sucos brasileiros acaba gerando sintomas como convulsões, paralisias e delírios.

De acordo com Caminhoá, o tempo necessário para qualquer planta venenosa produzir efeitos varia. Há envenenamentos lentos, mas há também plantas cujas propriedades tóxicas "excedem a tudo quanto se pode julgar!”. (Idem. Ibidem, p. 8) Por exemplo, com relação ao primeiro tipo de envenamento, ocorre por meio de substâncias como o mercúrio, o iodo, e a digitalina. (Idem. Ibidem, p. 9)

Caminhoá mencionou os estudos de João Teodoro Descourtilz (1796-1855) sobre os homicídios ocorridos pela propinação de venenos vegetais que os escravos cometiam em São Domingos e outras regiões das Antilhas. Contudo, discordava Caminhoá, ao exclamar que "e quantas vezes por insignificantes ofensas! Maldita escravidão! Foi ela, a meu ver, e não esses supostos frívolos motivos, que deu lugar a todos aqueles crimes execrandos.” (Idem. Ibidem, p. 9)

O autor considerou também que o uso do veneno é uma prática "reprovadíssima", e que é “duplamente detestável”, pois não apenas ceifa a vida do envenenado, e "porque é traiçoeira, tem sido averiguados, que demonstram ser possível com dozes fracionadas, e insensivelmente, ao cabo de um tempo mais ou menos longo, sacrificar uma ou mais vítimas”. (Idem. Ibidem, p. 9)

Num parágrafo, Caminhoá resumiu as suas considerações sobre a ação das plantas venenosas sobre o organismo dos seres vivos:

Quando a dose é elevada, e a absorção pronta, a morte de ordinário tem lugar mais ou menos rapidamente; quando a absorção é lenta por qualquer circunstância, ou quando as doses são fracionadas, apenas se manifestam os sintomas primordiais da intoxicação, ou esta segue lenta 
ou quase insensivelmente a sua marcha, até que em um dia há uma enérgica manifestação (químico-dinâmica), e a vítima sucumbe. (Idem. Ibidem, p. 9)

Em casos de dúvida sobre o efeito tóxico ou não de determinada planta, Caminhoá descreve um pequeno guia de experimentos que podem ser feitos no que ele chama de "animais inferiores". Nesses experimentos é necessário usar o suco de diversas partes da planta, pois cada parte pode ter um efeito, tomando cuidado para não aquecer esse suco a uma temperatura superior a $100^{\circ} \mathrm{C}$, pois altas temperaturas mudam muitos dos princípios do reino orgânico.

Outro fator que poderia alterar as propriedades da planta é o contato com substâncias ácidas ou alcalinas. Caminhoá sublinhou o cuidado que se deveria ter para evitar o contato das matérias cujas qualidades tóxicas se desejava saber, com os ácidos e álcalis, para se obter um juízo exato. Porque entre as primeiras e as últimas poderiam ocorrer algumas reações que poderiam mudar completamente suas propriedades não só tóxicas, mas também físico-químicas. (Idem.Ibidem, p. 10)

Caminhoá diz que quando uma substância testada em animais inferiores ocasiona o seu óbito, a mesma deve ser classificada como tóxica. Apesar disso, essa mesma substância venenosa, que é mortal para esses animais, pode não ser para animais de classes superiores, e vice-versa.

Caminhoá apresentou, em primeiro lugar, experimentos realizados pelo francês Jean-Louis Alibert (1768-1837). Ele aplicou doses de sublimado ao Ouriço, e outros animais de sua classe, sem que os mesmos fossem sacrificados. Por sua vez, num segundo momento, nutriu um roedor com raiz do Hyosciamus ou Meimendro, sem que houvesse o indício de substância tóxica. Porém, ao empregar a Cicuta, logo vieram a óbito. (Idem. Ibidem, p. 11)

$\mathrm{O}$ autor descreve um experimento feito por ele com animais inferiores:

Eu experimentei asfixiar ou intoxicar vários animais inferiores, com os vapores do álcool quase anídrico :- para isso empreguei um grande balão de vidro bitubulado, e por uma das aberturas fiz penetrarem vapores do liquido que, depois de ter estado em contacto com o clorureto de cálcio bem seco durante dois dias, destilei em uma retorta. - Estabeleci uma corrente de vapores alcoolicos nessas condições. Previamente coloquei uma aranha dos jardins, um cloporte, um iullus - uma borboleta diurna, e um gorgulho grande no interior do balão. (Idem. Ibidem, p. 11)

Caminhoá informou que o resultado desse experimento foi que a borboleta foi a primeira a morrer, em seguida a aranha, depois a do iullus, seguido pelo gorgulho, o último a morrer, depois de alguns minutos, foi o cloporte. (Idem. Ibidem, p. 11)

$\mathrm{O}$ estudioso argumentou que as suas experiências apresentadas, bem como as do francês Alibert, nada tinham de extraordinário. E, a seguir teceu a seguinte consideração: 
químico-física muito diversa, claro é que o modo de atuar dos ingesta não pode ser neles sempre idêntico. (Idem. Ibidem, pp. 11-12)

Segundo as pesquisas de Caminhoá, o clima tem o potencial de exercer mudanças nas propriedades das plantas, podendo assim torná-las venenosas ou não. Assim argumentou:

Uma planta pode ser venenosa em um país sob a ação de um certo clima, e modificar, ou perder aquela propriedade sob a ação de novos elementos modificadores, isto é, de climas opostos, ou pelo menos não idênticos. (Idem. Ibidem, p. 12)

Para exemplificar ele citou o pêssego, que na Pérsia seria venenoso e em outros países um “agradável alimento". Outro exemplo é a berinjela, venenosa nas Antilhas e um alimento comum no Brasil e na Europa. Isso se daria pela alteração química causada pela temperatura a qual a planta está submetida. (Idem. Ibidem, pp. 12-13)

Caminhoá argumentou que esta possibilidade de adquirir novas propriedades tóxicas ou perdêlas pode ser explicado pelas reações químicas ocorridas no interior da economia vegetal, as quais variam, quer com a temperatura total de cada ambiente ou somadas temperaturas parciais. Temperaturas mais elevadas facilitariam a exalação e a rapidez da circulação, além de diminuir o tempo em que a planta percorre as suas fases de vegetação. Caminhoá sublinhou ainda que o trabalho das secreções glandulares deve igualmente variar, conforme a intensidade térmica ou calorífica do meio ambiente. (Idem. Ibidem, p. 13)

Para finalizar a discussão, Caminhoá assim comentou: “ (...) a temperatura influi sobre o trabalho da vegetação e das secreções; ergo sobre o dos princípios tóxicos. Lembraremos que os venenos mais ativos talvez, e em maior número, acham-se na zona intertropical dos diferentes continentes, salvas poucas exceções." (Idem. Ibidem, p. 13)

Quanto à influência do terreno sobre as plantas venenosas, segundo Caminhoá, é difícil distinguir se a influência é exercida por questões químicas do solo ou pela mecânica simples. Nessa questão, autores como Augustin Pyrame de Candolle (1778-1841) e Hugo Von Mohl (1805-1872), compartilham a ideia de que o que influencia as características da vegetação é o estado físico, ou seja, a agregação maior ou menor das moléculas do solo. O professor Aylmer Bourke Lambert (1761-1842) ressalta a importância das qualidades químicas do solo, porém também considera a importância do estado de agregação do solo. Autores como Jules Thurmann (1804-1855) dão importância equivalente para esses dois fatores, químicos e físicos. (Idem. Ibidem, p. 14)

Em estudos feitos a partir da análise química de um grande número de plantas, notou-se que alguns princípios e compostos poderiam variar muito. Em contrapartida alguns são constantes, como a celulose, o lenhoso, a clorofila, o amido, etc. Algo observado nos estudos é que foram encontrados 
determinados constituintes inorgânicos em todas as plantas, quase de forma invariável, sendo eles, potassa, soda combinadas aos ácidos orgânicos ou inorgânicos, ácido carbônico, silícico, sulfúrico, clorídrico, entre outros, combinados com bases orgânicas e inorgânicas, a água, entre outros. (Idem. Ibidem, p. 15)

Caminhoá argumentou que se a nutrição se faz no seio da terra, ou melhor no meio em que se acham imersas as raízes, claro fica que nos vegetais devem predominar os princípios e compostos químicos, que existirem naqueles meios, ou que forem suscetíveis de formarem-se, graças as decomposições e recomposições dos agentes ali contidos.

Caminhoá prosseguiu argumentando que no seio da economia vegetal se dão inúmeras reações e formações de corpos novos, graças aos elementos que se encontram na substância propriamente da seiva, no líquido intercelular, no proto-plasma das células, e nas fibras das plantas.

Um processo químico importante que ocorre nas plantas é o de desoxidação, por meio do qual o oxigênio é desprendido, dando origem a novos produtos. Por meio desse processo de separação do oxigênio são formadas várias substâncias, como ácido tartárico, na uva e no tamarindo; ácido málico, na maçã e na uva; ácido cítrico na laranja, limão, lima e parreira; ácido gálico nas sementes do mangue; ácido mecônico nas Papoulas. Caminhoá argumentou que quando essa perda de oxigênio é maior, passamos dos ácidos às substâncias neutras como a celulose, o amido, a goma e o açúcar, produtos bastante abundantes nas plantas. (Idem. Ibidem, p. 16)

Para Caminhoá, a formação dos princípios tóxicos se pode explicar no "grande laboratório bioquímico". (Idem. Ibidem, p. 17) As substâncias tóxicas, segundo o autor, são em sua maior parte compostas de carbono, hidrogênio, oxigênio e azoto. (Idem. Ibidem, p. 17)

Em primeiro lugar, Caminhoá informou sobre as várias fontes do azoto, que no interior dos vegetais, fornecem o contingente para a formação dos princípios tóxicos. A seguir, comentou que quanto os corpos azotados, tóxicos ou não, que se encontram nas plantas, eles existiam desde a semente, ou se formaram à proporção que as "substâncias nitradas e amoniacais" trazidas pela seiva se puseram em contato com alguns agentes já formados em sua economia. (Idem. Ibidem, p. 18) Lembrou o autor que há, porém, substâncias azotadas tanto nas sementes, como nas células.

Caminhoá prosseguiu informando que é um princípio básico da Fisiologia Vegetal que um vegetal para germinar precisa de calor, ar, e humidade. Segundo o autor, esta última atua sobre o amido, ou a fécula existente nos cotilédones, ou no albúmen, dando lugar a uma modificação de suas moléculas, sem contudo alterar o a quantidade dos diversos elementos que a compõe. De acordo com o botânico, a diástase "é o corpo a que me refiro, cujos elementos existem na semente, e graças ao calor e humidade manifesta-se com todos os caracteres de um fermento, converte o amido em Dextrina, isto 
é, graças a sua ação de catalise um novo arranjo das moléculas do primeiro tem lugar”. (Idem. Ibidem, pp. 18-19)

Sobre o processo que tornou o amido solúvel, assim comentou Caminhoá:

\begin{abstract}
Não careço dizer que a natureza sempre sábia em suas obras produziu aquela transformação a fim de tornar solúvel o amido que tem de ser absorvido e levado para o interior das células da semente, e produzir a seiva primitiva, que limita seu curso provavelmente à simples giração, ou circulação intra-celular.

A diastase pois é a matéria azotada da semente; como tal ela se acha classificada pelo professor Gerhardt e outros. (Idem. Ibidem, p. 19)
\end{abstract}

Caminhoá sublinhou também que experiências como as de Jan Ingenhouze (1730-1799), Nicolas Théodore de Saussure (1767-1845) e Johann Heinrich Robert Göppert (1800-1884), mostraram que durante a germinação das sementes diminuiu o azoto do ar atmosférico. (Idem. Ibidem, p. 19)

De acordo com Caminhoá, é indispensável que as substâncias nutritivas que têm de ser absorvidas pelas raízes sejam solúveis na água, pois que, conforme argumentou o autor, "como se acha demonstrado em trabalhos de Química Fisiológica, os corpos insolúveis, ainda quando reduzidos a pó subtilíssimo em suspensão nos líquidos, não são absorvidos.” (Idem. Ibidem, p. 20) E, alertou:

experiências que pareciam inatacáveis, que por serem feitas por sábios e honestos Naturalistas, quer pelos seus resultados (...) não merecem a aceitação que mereceram até há pouco. (Idem. Ibidem, p. 19)

Caminhoá sublinhou que experiências recentes demonstram que a tinta de escrever não é absorvida com a sua cor negra, "se as extremidades radiculares estiverem sem solução alguma de continuidade". (Idem. Ibidem, p. 20) E, prosseguiu:

No caso contrário vê-se a substância negra muito tênue percorrer não os vasos sevosos, porém todos os capilares que estiverem em comunicação com a solução de continuidade embebida, e, segundo os fisiologistas de então, isto servia para indicar o modo e lugar por onde ascendia a seiva. (Idem. Ibidem, p. 21)

Seguindo os argumentos do cientista, é princípio irrefragável que a nutrição se faz nas plantas com os princípios terrosos ou minerais solúveis na água. E, em função dessa consideração, dois corolários podem ser estabelecidos. O primeiro estabelece que a planta que fosse transplantada para um terreno que possuísse arsênico ou mercúrio, poderia se tornar prejudicial ou não para a saúde de quem a consumisse conforme o minereo daqueles metais for solúvel, ou insolúvel na água. Essa absorção poderia transformar uma planta comum em venenosa. Porém, Caminhoá acredita que é uma 
possibilidade remota, pois “os minereos daqueles como dos outros metais venenosos são insolúveis". (Idem. Ibidem, p. 21)

O segundo corolário apresentado por Caminhoá é aquele que considera que, se suceder que uma planta, cujo princípio tóxico seja decomposto, pelos carbonatos alcalinos, sulfatos, entre outros, achase transplantada, ou tenha nascido em terrenos sódicos, ou de potassa carbonatados, ou sulfatados, sem sombra de dúvida podem suas propriedade venenosas ser modificadas ou completamente abolidas. E, finalizou argumentando que: "Inúmeras hipóteses realizáveis facilmente podem ser apresentadas, e aceitas sem escrúpulo, que provem essa verdade”. (Idem. Ibidem, p. 21)

As estações do ano também influenciam as plantas. De acordo com Caminhoá, "a seiva e suas propriedades variam conforme as estações”. (Idem. Ibidem, p. 22) Na primavera, a seiva chamada bruta "quando chega às sumidades da planta, contém muito mais princípios orgânicos do que aquela que se recolhesse nas proximidades da raiz". (Idem. Ibidem, p. 22) Por sua vez, no outono, “o tronco e a casca se enchem de fecula e outros nutrientes e o cambium se enche de uma substância granulosa que o iodo colore em amarelo. A fecula se converte em dextrina e açúcar”. (Idem. Ibidem, p. 22)

Caminhoá diz que as características tóxicas de uma planta podem variar de acordo com sua idade. Algumas são alimentícias quando novas e se tornam tóxicas quando florescem, como no caso da alface e algumas chicórias. Além disso, o princípio tóxico das plantas pode estar em partes diferentes dela, nas sementes, flores ou nas raízes, podendo em cada uma delas oferecer uma propriedade. Esse é o caso da Mandioca, citado por Caminhoá. (Idem. Ibidem, p. 23)

$\mathrm{O}$ autor salienta que em climas quentes, quando há constantemente o calor, existe uma aceleração nas fases das plantas, possibilitando mais de um ciclo completo por ano, ou duas gerações de brotos ou três. Então, Caminhoá coloca a questão: “Quem ignora entre nós, que no Norte do Brasil há duas colheitas de laranjas e de outros frutos?” (Idem. Ibidem, p. 23)

Por sua vez, na primavera, argumenta Caminhoá, quando a ascensão da seiva bruta tem lugar, e se o laboratório químico-vital propriamente dito só pode funcionar, depois que a seiva tem sido elaborada, salienta o autor que "as propriedades tóxicas devem tornar-se saliente depois da primavera. Esta é regra geral." (idem. Ibidem, p. 23)

Salienta ainda Caminhoá que não tendo "a seiva a mesma composição química nas diferentes estações do ano, não pode a planta ser igualmente venenosa em todas elas”. (Idem. Ibidem, p. 23)

A proximidade ou afastamento com os oceanos, segundo o autor, confere um certo fácies à vegetação, fato que a torna característica.

De acordo com Caminhoá, as plantas que estiverem mais próximas do mar são quase sempre rijas e possuem uma organização especial, uma vez que precisam ser resistentes aos ventos, e para não ter os seus tecidos e sucos alterados pelo clorureto de sódio e outros sais. (Idem. Ibidem, p. 24) 
Caminhoá considerou que as águas dos mares são mortais para algumas plantas. Contudo, para outras, aquelas ocasionam reações ou decomposições de qualquer natureza, não contêm os princípios necessários para a nutrição, e numerosos raphides que se formam no interior das células impedem a giração. Daí, segundo argumento de Caminhoá, alguns naturalistas afirmarem que o clorureto de sódio altera a composição dos agentes químico-vegetais nas plantas. O autor argumenta, por sua vez, que o clorureto de sódio também altera os "princípios tóxicos, ipso factu; e essa conclusão já tem de há muito sido aceita na prática de alguns observadores”. (Idem. Ibidem, p. 24)

Caminhoá mencionou uma afirmativa que diz que "não existem plantas venenosas nas praias". Entretanto, o autor questionou a consideração supracitada:

a proposição que nega propriedades tóxicas à toda e qualquer planta marítima peca por absoluta; ela pode muitas vezes perder total, ou parcialmente aquela propriedade; porém uma Loganiacea, uma Apocynacea, uma Solanacea (virosa), etc., embora marítimas, são quase sempre venenosas. A mais venenosa de todas as plantas talvez, a Mancenilha, dá nas praias salgadas das Antilhas. (Idem. Ibidem, pp. 24-25)

Segundo o autor, alguns "fito-fisiologistas" têm tentado demonstrar que os sais contidos nos terrenos próximos ao mar influem sobre os venenos. Caminhoá concorda em alguns casos, em outros discorda. No caso dos cogumelos, por exemplo, ele concorda:

Está demonstrado que o clorureto de sódio, se não decompõem completamente a fungina, princípio ativo daqueles vegetais, pelo menos a torna inócua, o que quer dizer, modifica-lhe a composição; pelo que é de regra na Europa e outros lugares, onde se usa em grande quantidade dos cogumelos como alimento, nos casos de dúvida se os póem contato com o sal, depois do que podem ser impunemente comidos, segundo afirmam alguns botânicos. (Idem. Ibidem, p. 25)

Ao comentar sobre as partes tóxicas das plantas, Caminhoá iniciou citando Humboldt ${ }^{1}$, quando este afirma que: "Mas a ação vital, esse jogo de afinidades químicas, de que só conhecemos o efeito, dá origem na mesma planta às produções mais heterogêneas.” (Idem. Ibidem, p. 25) E, Caminhoá considerou tal afirmação verdadeira.

Caminhoá considerou válido que em uma mesma planta, conforme o órgão ou planta que se estuda, bem como experimentando sobre os animais, os resultados tóxicos podem variar, ou mesmo variam muito às vezes. $\mathrm{O}$ autor citou então diversos exemplos como o Eseré ou Fava de Calabar (Phytostygma venenosum), que se "experimentar as sumidades florais, ou as folhas, casca, entre outros, apenas pequenos sintomas de envenamento pela Eserina, seu princípio ativo, ocorrerão" (Idem. Ibidem, p. 26); o exemplo da laranjeira (Citrus aurantium): “tem as raízes amargas e tônicas, e bem

${ }^{1}$ Caminhoá citou Alexander Von Humboldt (1769-1859). No caso a obra Voyage de Humboldt et Bonpland. Plantes Équinoxiales, 1808. 
assim o cortical, as folhas completamente desenvolvidas são estomáquicas e ligeiramente excitantes, os brotos, ou renovos e as flores anti-espamódicos, o pericarpo excitante e fortemente aromático, o líquido contido no endocarpo, ou o suco do fruto é acido e temperante, as sementes tônicas e amargas" (Idem. Ibidem, p. 26); outro exemplo fornecido é o da mandioca (Jatropha manihot de Linn): “oferece as folhas alimentícias, e sem ação tóxica sensível (...) o fruto da planta é venenosíssimo, segundo tenho aprendido; suas raízes contêm duas partes muito distintas, e mesmo diametralmente opostas sob o ponto de vista alimentar: uma fuculenta, de que se prepara a farinha, que serve de alimento à máxima parte da população, e outra eminentemente tóxica, a manipuera" (Idem.Ibidem, p. 26); a urtiga foi outro exemplo fornecido: “em suas folhas tem um princípio urente, produto de glândulas pediculadas, que as cobrem; o mesmo se dá no caule: suas raízes são diuréticas, seus frutos e sementes nenhuma particularidade notável apresentam, além de serem mucilaginosos, e ligeiramente adstringentes" (Idem. Ibidem, p. 26)

Caminhoá argumentou que não se pode absolutamente e sempre afirmar que, pelo fato de uma planta conter princípios tóxicos, qualquer uma de suas partes possa vir a produzir a morte, ou graves perturbações da saúde. $\mathrm{O}$ autor considerou que no geral o princípio predominante em um vegetal pode ser encontrado em todas as partes da planta, de onde se deduz que de uma parte considerada inócua de uma planta se pode extrair doses mínimas de substâncias tóxicas, e que somadas com outras iguais, podem resultar uma quantidade, cuja ação seja muito enérgica. Exemplo disso pode ser visto no cajueiro, onde se encontra a substância caustica e acre também nas suas folhas, porém em dozes muito pequenas se comparadas às do pericarpo. (Idem. Ibidem, p. 27)

Como já dito, quando se há dúvidas sobre as propriedades tóxicas de uma planta, é necessário, segundo Caminhoá, fazer experimentações em “animais inferiores”. Segundo o autor,

Pondo de parte as Associações Zoófilas inglesas etc., que procuram opor certas barreiras aos estudos de Fisiologia experimental, Toxocologia, etc., só para que não sofram os pobres animaizinhos(!), em toda parte do mundo civilizado, onde se cultiva as ciências com afã - é este o meio comumente empregado, afim de com segurança e conhecimento de causa poder decidir: $1^{\circ}$ se uma planta, ou substância é, em geral, tóxica; $2^{\circ}$ quais os sintomas que oferecem os envenenamentos por elas ocasionados; $3^{\circ}$ quais os antídotos de que pode com segurança lançar mão o prático?

Assim, creio eu, é melhor ser filântropo do que zoófilo. (Idem. Ibidem, pp. 27-28)

Caminhoá considerou conveniente e indispensável a realização de experimentos com os animais e plantas. Para um resultado satisfatório dos experimentos, algumas precauções deveriam ser tomadas. Primeiramente, com as plantas, deve-se atentar para a amostra não ser exposta a um calor intenso, pois a temperatura pode mudar alguns de seus princípios, o mesmo vale para a exposição a 
ácidos alcalinos e sais, que pelas mesmas razões podem dar lugar à formação de novos corpos, ou a combinações tais que façam perder as propriedades tóxicas, ou as adquiriam, quando não tivessem.

Caminhoá argumentou que o Oxalato de cal pode ser encontrado em uma planta, e ser impunemente ingerido pelos animais. Caso, porém, a ação de um ácido for tal que se apodere daquela base, pode ocorrer o envenenamento.

Sublinhou que para o ácido oxálico há inúmeras objeções, que tem importante valor nos laboratórios de química, porém não podem ser aceitas no grande laboratório da química dinâmica.

Argumentou também que quimicamente falando seria inadmissível a presença de sílica pura no interior das células. Contudo, graças a ação de uma força poderosa, isto sucede não poucas vezes.

Caminhoá argumentou que dizem que não convinha, para que o botânico toxicologista emitisse um parecer consciencioso sobre uma planta suspeita, misturá-la com os alimentos adubados, ou ácidos, entre outros.

Alertou para o fato de que o veículo em que se faz a solução dos princípios das plantas a analisar é uma circunstância de máxima importância, e que não convinha ser esquecida. Ademais, também deveríamos estar atentos para a escolha da parte a empregar, uma vez que um mesmo vegetal pode oferecer uma de suas partes tóxica, outra medicamentosa, e assim por diante.

Considerou que os sucos expressos e recentemente extraídos das plantas são os verdadeiros meios de incutirem a convicção sobre as conclusões a que se quer alcançar, uma vez que as substâncias tóxicas, se existirem já formadas, aí estarão na condição de serem os sucos recentemente extraídos. E, ainda alertou sobre a emulsão de amêndoas doces:

\footnotetext{
Bem sabeis que a emulsão de amêndoas doces, que é inocente pode tornar-se venenosíssima, desde que em um fermento especial (a sinaptase, se bem me lembro) lhe for ajuntado. Sabe-se a prontidão com que os sucos vegetais, principalmente em nosso clima entram em fermentação. E quem nos pode assegurar que no caso de que nos ocuparmos não se possa dar a formação de um desses fermentos capazes de determinarem a formação de um corpo tóxico?

Essa cautela eu a apresento apenas, sem poder assegurar sua indeclinável necessidade. (Idem. Ibidem, p. 29)
}

A seguir, Caminhoá passou a comentar sobre as cautelas relativas aos animais. Em primeiro lugar, ele tratou da escolha do animal, e, a seguir, das condições especiais para a experiência.

O tipo de animal empregado à pesquisa depende do seu fim. Se for apenas para testar se a planta é tóxica ou não, qualquer um serviria. Nos Estados Unidos e Europa, coelhos e porcos da índia são utilizados, muito por conta de seu baixo preço e grande taxa de reprodução. Para experimentos mais complexos, em caso de decidir de sua inocuidade relativamente ao homem, poderiam ser utilizados animais como orangotangos. Segundo Caminhoá, o cão seria o animal mais próprio para os 
experimentos, por seus hábitos alimentares e por compartilhar o meio com o ser humano. (Idem. Ibidem, p. 31)

Seguindo a ideia do Sr. Dr. Francisco Ferreira de Abreu (1823-1885),seria aconselhado a escolha de um cão de rua, pois assim além do benefício do resultado do experimento, haveria o benefício de tirar um cão da rua que poderia morder alguém. A dose empregada em cães podia variar de $1 / 3$ até $2 / 3$ da dose humana, dependendo do tamanho do animal. (Idem.Ibidem, p. 31)

Para o experimento, é preferível que o estômago do cão se encontre vazio antes da ingestão do veneno. Um problema que pode acontecer é o cão vomitar. Para contornar a situação, Caminhoá indica laquear o esôfago do animal durante algumas horas, podendo mais tarde ser retirado o laço, ou o fio. E, a seguir afirma: "Se a substância sobre que versar a experiência for tóxica realmente, e o animal sucumbir, não há inconveniente na ligadura; se pelo contrário escapar, se curará facilmente mais tarde.” (Idem. Ibidem, p. 31)

Caminhoá também alega que tal processo da laqueadura acaba por ter pontos negativos, como dificultar a visualização de certos sintomas do envenenamento como a sede e a constrição da garganta, assim como os sintomas de inflamação da laqueadura podem gerar dúvidas no experimentador. É indicado, quando possível, a substância ser aplicada pelo método hipodérmico, pois contorna tais problemas. (Idem. Ibidem, p. 32)

Ao fim do texto Caminhoá enfatiza a importância da probidade cientifica, "norte único dos verdadeiros cultores da ciência", não permitindo que um cientista seja leviano e afirme que uma planta é tóxica para os humanos por ser tóxica para outros animais, tais como aves e peixes. Ou seja, alguns venenos podem ser fatais para determinados tipos animais e inofensivos para os humanos e vice-versa. São citados exemplos pelo autor, como o caso do arrebenta cavalo e a sua congênere no norte, a melancia da praia, fatais para solípedes e ruminantes, e praticamente seus furtos são inofensivos para as crianças. Outro exemplo fornecido foi o da mancenilha, que é comida por peixes e caranguejos, porém mata outros tipos de animais. E, por fim, o exemplo da erva-moura, venenosa para animais superiores, e ingerida sem problemas por algumas aves e peixes. (Idem. Ibidem, p. 32) E, para finalizar, citou como referência o médico holandês Pison, em sua História Natural e Médica do Brasil, para demonstrar essa verdade.

Na segunda parte do texto, intitulada Das Plantas Tóxicas do Brasil em Particular, Caminhoá explicou sobre o método a ser utilizado para comentar sobre as referidas plantas. $\mathrm{O}$ autor escolheu por começar falando das plantas que tem uma ação venenosa mais enérgica, sem deixar de seguir o roteiro científico, assim trabalhando sua classe, família e gênero. (Idem. Ibidem, p. 35)

Em seguida, Caminhoá enfatiza a importância nos estudos das ciências naturais da necessidade de ser fiel na exposição de uma planta, quer seja dos caracteres botânicos conforme aqueles que a 
classificaram, quer segundo suas condições de existência, sua pátria, bem como referir os nomes de quem a classificou ou suas abreviaturas. E, justificou: “ porque isto serve, para, em presença de uma amostra, poder-se fazer o estudo, conforme o que disser quem a estudou minuciosamente; e bem assim para poder-se decidir no caso de erro, ou dúvida, recorrendo à fonte pura”. (Idem. Ibidem, p. 35) Ao proceder dessa forma, Caminhoá argumentou que "será sempre mais vantajoso, pelo menos o mais aproximadamente possível da exposição dos que estudaram as plantas em primeiro lugar, e nos pontos onde espontaneamente elas se desenvolvem”. (Idem. Ibidem, p. 35)

Caminhoá informou que certas famílias predominam em espécies tóxicas, dentre as quais os exemplos que serão trabalhadas, e que naturalmente se desenvolvem no Brasil, são os das Asclepiaceas, Apocinaceas, Loganiaceas, Euphorbiaceas. (Idem. Ibidem, pp. 35-36)

Caminhoá diz ter se preocupado em utilizar as fontes mais modernas para as classificações, porém deixou claro a dificuldade para se manter atualizado nos progressos da Organografia, Anatomia e Fisiologia vegetais. Segundo o autor, isso ocorre devido às descobertas diárias na área, gerando denominações e classificações novas, ao ponto de catálogos científicos "chegarem a passar de quinze ou dezesseis anos de atraso!"' (Idem. Ibidem, p. 36) As dificuldades para o estudo foram tamanhas que o autor admite a possibilidade de faltas em seu trabalho, em suas palavras, "Grandes foram as dificuldades com que lutamos; restando nos o desprazer de não podermos considerar depurado de faltas, principalmente deste gênero, o nosso trabalho". (Idem. Ibidem, p. 36)

Caminhoá informou que a seguir ao reconhecimento das plantas tóxicas e classificá-las, seriam apresentados os nomes científicos e vulgares das mesmas, o local de ocorrência, observações peculiares, fato que facilitaria o estudo da sua classificação e descrição. ${ }^{2}$

\section{CONSIDERAÇÕES FINAIS}

A análise da obra Das Plantas Tóxicas do Brasil deixa transparecer a produção do conhecimento científico no Império do Brasil. Caminhoá nos apresenta um estudo denso, aprofundado, detalhado, bastante rico em informações, exigindo conhecimentos especializados, no caso a Botânica. A obra apresenta citações de importantes nomes da ciência oitocentista, bem como um conjunto variado de sistemas de classificação utilizados para nomear e classificar as plantas tóxicas do Brasil. Caminhoá era um letrado da sociedade imperial, especialista no conhecimento botânico, inserido nas instituições científicas, e atualizado com as questões científicas que eram discutidas no momento de produção do

\footnotetext{
${ }^{2}$ Torna-se impossível apresentar nas páginas deste artigo o conjunto das plantas tóxicas mencionadas por Caminhoá. Tal tarefa ficará para uma próxima oportunidade.
} 
seu texto. Das Plantas Tóxicas... constitui-se como uma importante contribuição do autor para o processo de emergência e consolidação das ciências naturais no Brasil oitocentista. 


\section{REFERÊNCIAS}

\section{Textos de Joaquim Monteiro Caminhoá:}

CAMINHOÁ, Joaquim Monteiro. Das Plantas Tóxicas Do Brasil. Tese De Concurso Para a Cadeira De Botânica Médica Da Faculdade De Medicina Do Rio De Janeiro. Rio de Janeiro: Tipográfica Perseverança, 1871.

\section{Artigos, Livros e Teses:}

Casa de Oswaldo Cruz / Fiocruz. Dicionário Histórico-Biográfico das Ciências da Saúde no Brasil (1832-1930). Verbete Sociedade Velosiana de Ciências Naturais. In: http://www.dichistoriasaude.coc.fiocruz.br (Acessado no dia 05/06/2020).

VARELA, Alex Gonçalves. Joaquim Monteiro Caminhoá: um médico ilustrado do Império do Brasil, 1858-1896. História, Ciências, Saúde-Manguinhos. Rio de Janeiro, v.26, n.1, jan.-mar. 2019, pp.335345.

VARELA, Alex Gonçalves; VIEIRA, Gabriel; PEREIRA, João Marcos Rocha (Orgs.). Um Botânico no Império do Brasil: a Trajetória de Joaquim Monteiro Caminhoá (1858-1896). Rio de Janeiro: Quártica, 2021. 